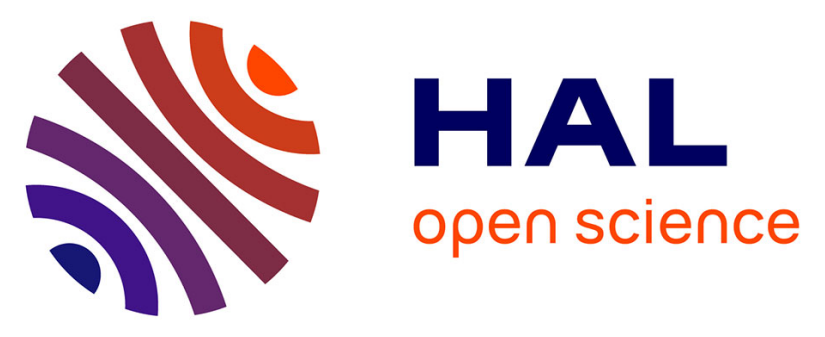

\title{
Sequential modeling to understand and predict differentiated flowering time responses to warming in apple tree in contrasting climatic regions
}

G. Malagi, A. El Yaacoubi, I. Citadin, Marc Bonhomme, Isabelle Farrera, Jean-Luc J.-L. Regnard, Jean-Michel Legave

\section{To cite this version:}

G. Malagi, A. El Yaacoubi, I. Citadin, Marc Bonhomme, Isabelle Farrera, et al.. Sequential modeling to understand and predict differentiated flowering time responses to warming in apple tree in contrasting climatic regions. X International Symposium on Modelling in Fruit Research and Orchard Management, International Society for Horticultural Science (ISHS). INT., Jun 2015, Montpellier, France. 10.17660/ActaHortic.2017.1160.28 . hal-02737778

\section{HAL Id: hal-02737778 \\ https://hal.inrae.fr/hal-02737778}

Submitted on 2 Jun 2020

HAL is a multi-disciplinary open access archive for the deposit and dissemination of scientific research documents, whether they are published or not. The documents may come from teaching and research institutions in France or abroad, or from public or private research centers.
L'archive ouverte pluridisciplinaire HAL, est destinée au dépôt et à la diffusion de documents scientifiques de niveau recherche, publiés ou non, émanant des établissements d'enseignement et de recherche français ou étrangers, des laboratoires publics ou privés. 
Sequential Modeling to Understand and Predict Differentiated Flowering Time Responses to Warming in Apple Tree in Contrasting Climatic regions

G. Malagi

Federal University

Eliseu Maciel Agronomy College

Pelotas, Rio Grande do Sul, Brazil

I. Citadin

Federal Technological University

Agronomy Department

Pato Branco, Paraná, Brazil

\author{
A. El Yaacoubi \\ University Moulay Ismail \\ Faculté des Sciences \\ Meknès, Morocco \\ M. Bonhomme \\ INRA and Université Blaise Pascal \\ UMR PIAF \\ Clermont-Ferrand, France
}

I. Farrera, J.L.Regnard and J.M. Legave

INRA and Montpellier SupAgro, UMR AGAP

Montpellier, France

Keywords: fruit tree, floral phenology, dormancy release, chilling, heat, global warming

\begin{abstract}
Long-term series of temperature and apple flowering date were set up for seven climate-contrasting locations in western Europe. A statistical analysis and a sequential modeling approach has been used to understand how global warming impacted dormancy release and flowering time in recent past and will impact in the future. Selected models explained up to $90 \%$ of the flowering date variability in Europe. Both the statistical analysis and the modeling of flowering dates supported that flowering advances in European temperate climates were clearly linked to faster fulfillments of heat requirements due to marked spring warming since the end of the 1980s. Delays of dormancy release, linked to chill temperature declines, were likely to also occur especially in the French Mediterranean region, which can explain a stationarity of the flowering date series since the beginning of the 2010s. Predicted changes until the end of the 21st century in Mediterranean region would confirm both a stationarity of flowering time and increasing delays of dormancy release. In addition, historical series of temperature and flowering dates were set up for three mild climate locations (one in Northern Morocco and two in Southern Brazil). While a flowering advance and a spring warming were statistically supported in Morocco, both flowering date and temperature series have generally remained stationary in the Brazilian locations. Finally, differentiated responses of apple tree flowering time were highlighted at the world scale in relation with differentiated warming contexts. Moreover, both sequential models selected from European data and models selected from Moroccan or Brazilian data appeared inadequate to simulate the observed flowering dates in the Moroccan and Brazilian locations. This cast a doubt on the sequential modeling relevance to predict dormancy release and flowering changes in the future warming context of European regions.
\end{abstract}




\section{INTRODUCTION}

As phenological events are highly responsive to temperature, abundant studies have focused on bud phenology and have outlined flowering advances as main responses to global warming. Flowering advances were highlighted for the apple tree in various warming contexts of the northern hemisphere (Wolfe et al., 2005; Guédon and Legave, 2008; Fujisawa and Kobayashi, 2010), while they have been scarcely reported in the southern hemisphere (Darbyshire et al., 2013). One likely warming impact during bud endodormancy is a delay in the fulfillment of chill requirements and consequently a delay in the time at which perennial plants become receptive to heat temperatures (Legave et al., 2015). A comprehensive assessment of differentiated responses to warming in temperate perennial plants must thus include the potential impacts on the fulfillment of both chill and heat requirements (Schwartz and Hanes, 2010). The sequential chill-growth model was therefore commonly used for analyzing flowering times in deciduous fruit trees (Darbyshire et al., 2014). However, most of the studies in fruit trees have reported warming responses and sequential modeling results in only one or a few locations submitted to similar climatic contexts, whereas it has been demonstrated that a given species can have varying responses in different locations (Primack et al., 2009). Therefore, the use of phenological series recorded in contrasting climatic regions for same plant materials can provide an appropriate framework to improve the modeling of warming responses. Our goal was thus to test sequential modelling of flowering time at global scale, including both temperate and mild cropping regions. Apple tree offers a relevant study plant because of its worldwide cultivation and relatively high chill requirements. We aimed to answer the following key questions: (1) Are flowering time changes differentiated over a large geographic cropping area? (2) How are flowering and temperature changes linked? (3) Is the sequential chill-growth model suitable for projection analyses?

\section{MATERIALS AND METHODS}

\section{Collection of flowering dates}

An international network on apple tree phenology has been established between research institutes in six countries. We selected seven locations in western Europe, one in northern Morocco and two in southern Brazil (Table 1). The eight locations in the northern hemisphere included contrasting cropping regions with a corresponding range of contrasting climatic conditions during the dormancy and flowering phases, from cold continental climates in Europe to a mild climate in Morocco. While situated at high altitude to favor apple cropping, the two Brazilian locations in the southern hemisphere were characterized by mild climates (mean temperature up to $11^{\circ} \mathrm{C}$ ). Flowering dates were recorded for the early blooming stage (BBCH 61) and the full blooming stage (BBCH 65). They were recorded on adult trees in long-term orchards using similar observation procedures. To compare longterm flowering series for same plant materials, records from cultivars growing worldwide were used. We therefore chose Golden Delicious (GD) for which records were available at all locations. In addition, records for Gala and Fuji were used since these cultivars were mainly grown in southern Brazil, but also in Europe. The three cultivars were characterized by high 
chill requirements. Our data set consisted of 30 flowering date series including series of stages 61 and 65 (16 of them corresponding to temperate conditions and 14 to mild).

\section{Statistical modeling of flowering and temperature series}

We used multiple change-point models for analyzing the flowering and temperature series at each location (see Legave et al., 2015). Compared to a previous study (Guédon and Legave, 2008), we extended the statistical modeling framework in order to test not only piecewise constant models but also piecewise linear models that include simple linear regression models when no change point can be detected.

\section{Simulation of dormancy release and flowering time by sequential modeling}

Modeling was based on the usual assumption that chill and heat temperatures have successive and independent effects on the endodormancy release and post-dormancy growth that lead to flowering. We tested combinations of seven chill functions and four heat functions covering a large diversity of mathematical laws. The optimal combinations were compared to thermal time modeling (only heat function). This study focused on the modeling of BBCH 61 date for GD for which a great number of contrasting data was available (Table 1). Maximizing the $\mathrm{R} 2$ value between the observed and simulated flowering dates and minimizing the corresponding RMSE values were used to select optimal models. The consistency of model parameters with the biological knowledge of bud dormancy and growth was also considered. The selected models were validated from location and year data not used in model fitting (see Legave et al. 2013). Both dates of dormancy release and flowering stages were simulated in recent past for each location of Western Europe, Northern Morocco and Southern Brazil. Concerning predicted dates in long term (2100), preliminary works were conducted for the European locations. We used temperature values generated by the ARPEGE climatic model platform (http://www.drias-climat.fr/) and two Representative Concentration Pathway scenarios based on different radiative forcing $\left(\mathrm{W} / \mathrm{m}^{2}\right)$ pathways (IPCC, 2013): moderate forcing 4.5 and pessimistic forcing 8.5.

\section{RESULTS}

\section{Flowering time and warming changes in recent past}

Abrupt flowering advances have been observed in all European locations since the end of the 1980s. They were more pronounced in continental than in oceanic locations (10 vs. 6-7 days), while the shortest advance was found in the French Mediterranean location (Nîmes) (Fig. 1). Such advances may be explained by abrupt increases of mean temperatures during the fulfillment of heat requirements (Legave et al., 2013). Nevertheless, when the flowering dates were considered over longer periods (Legave et al., 2015), the statistical analysis outlined a stationarity of flowering date series in Nîmes which would be more probable than a continuous flowering advance as in the other European locations. A statistically flowering stationarity in Nîmes in long term (forty years) could be explained by the addition of significant and similar increases of both mean temperatures during the 
fulfillments of chill and heat requirements (contrary to the other European locations). In Morocco, a flowering advance was significantly observed since the beginning of the 1990s (later than in Europe), in relation with higher rates of heat requirement fulfillment as in Europe (except Nîmes). In contrast, both flowering date and temperature series have generally remained stationary in the Brazilian locations considering a long term (forty years).

\section{Flowering time modeling and predicted changes}

Sequential models selected from European data were able to explain up to $90 \%$ of the flowering date variability in Europe; this was $17 \%$ lower for thermal time models (Legave et al., 2013). Simulations of dates of dormancy release and flowering time complemented the understanding of flowering time advances. As an illustration, Figure 2 shows assessments of durations of both the chill period and the heat period to reach the stage BBCH 61 in GD before and after the end of the 1980s at four climate-contrasting locations, according to the selected F1Gold1 model (Legave et al., 2013). A mean decrease of the heat period was assessed at all locations ( 7 to 12 days), while the simulations also outlined a lower mean increase of the chill period. These two unequal and opposite mean changes may explain flowering advances at all locations since the end of the 1980s up to the 2000s. Nevertheless, it should be noted that the French Mediterranean location (Nîmes) was characterized by the highest changes for both the decrease of the heat period and the increase of the chill period. In contrast, both sequential models selected from European data and models selected from Moroccan or Brazilian data appeared inadequate to simulate the observed flowering dates in the Moroccan and Brazilian conditions (unpublished data).

Long-term projections of dormancy release and flowering dates (BBCH 61 and 65) in the French Mediterranean location suggest a stationarity of the flowering date for the stage 61 a slight flowering advance for the stage 65, while trends toward later dormancy releases are suggested (more marked with the $8.5 \mathrm{RCP}$ scenario). In contrast, clear flowering advances are only predicted in the French Oceanic location (Angers), while trends toward later dormancy releases are only suggested for the $8.5 \mathrm{RCP}$ scenario (less marked than in Nîmes) (Fig.3).

\section{DISCUSSION}

The responses of flowering phenology to temperature increases in temperate fruit tree species have rarely been investigated in contrasting climatic regions. Our results showed that this is an appropriate approach to highlight differentiated responses to diverse warming contexts, which would potentially combine different chill accumulation declines and heat accumulation increases. We thus provided a new overview in space and time of flowering time changes in apple tree since our results showed advances or stationarity of flowering dates, contrary to previous studies that only reported flowering advances. An interesting change was outlined in the French Mediterranean region that experienced flowering advances since the end of the 1980s until the beginning of the 2000s and a flowering stationary since the beginning of the 2010s. Interestingly, similar stationary series were supported in Mediterranean region and in subtropical region of southern Brazil. However, such similar flowering responses (statistically) would result from contrasting warming contexts, i.e. 
temperature increases during both the chill and heat periods in southern France vs. no temperature changes during the corresponding periods in southern Brazil (Legave et al 2015). The sequential modeling approach of flowering time appeared appropriate to complement the understanding of flowering changes (advance/stationarity) in the recent warming context of temperate European regions. In contrast, it was not an appropriate approach to adequately simulate flowering time in warming contexts of mild regions such as northern Morocco and southern Brazil. This may thus cast a doubt on the sequential modeling relevance to predict dormancy release and flowering changes in the future warming context of European regions. Recent results of Darbyshire et al. (2014) also suggest a potential deficiency in the sequential chill-growth model to predict flowering time when applied to projected climate conditions in southern Australia.

\section{CONCLUSIONS}

The collection of flowering date series recorded in contrasting climatic locations proved to be an appropriate approach in a temperate fruit species, such as apple tree, for identifying differentiated flowering responses to different warming contexts in recent past. Particularly, the statistical analysis pointed out the vulnerability of Mediterranean regions where apple tree is a native crop and might shift into responding more to chill decline as warming continues. The sequential modeling of flowering time contributed to the understanding of warming impacts in the recent context of temperate regions. Nevertheless, this modeling approach appeared not structured enough to accurately capture the chill and heat effects in mild regions. This supports the need to research more structured models regarding the combination or interaction between chill and heat accumulations.

\section{Literature Cited}

Darbyshire, R., Webb, L., Goodwin, I., Barlow, E.W.R. 2013. Evaluation of recent trends in Australian pome fruit spring phenology. Int. J. Biometeorol. 57, 409-421.

Darbyshire, R., Webb, L., Goodwin, I., Barlow, E.W.R. 2014. Challenges in predicting climate change in pome fruit phenology. Int. J. Biometeorol. 58, 1119-1133.

Fujisawa, M., Kobayashi., K. 2010. Apple (Malus pumila var. domestica) phenology is advancing due to rising air temperature in northern Japan. Glob Chang Biol 16:26512660

Guédon, Y., and Legave, J.M. 2008. Analyzing the time-course variation of apple and pear tree dates of flowering stages in the global warming context. Ecological Modeling 219, 189-199.

IPCC 2013. Working Group I Contribution to the IPCC Fifth Assessment Report. Climate Change 2013: the Physical Science Basis. Cambridge University Press, Cambridge, UK.

Legave, J.M., Blanke, M., Christen, D., Giovannini, D., Mathieu, V., Oger, R. 2013. A comprehensive overview of the spatial and temporal variability of apple bud dormancy release and blooming phenology in Western Europe. Int. J. Biometeorol. 57, 317-31. 
Legave JM, Guédon Y, Malagi G, El Yaacoubi A, Bonhomme M. 2015. Differentiated Responses of Apple Tree Floral Phenology to Global Warming in Contrasting Climatic Regions. Front Plant Sci 6:1054.

Primack, R.B., Ibanez, I., Higuchi, H., Don Lee S., Miller-Rhushing, A.J., Wilson, A.M., et al. 2009. Spatial and interspecific variability in phenological responses to warming temperatures. Biological Conservation 142: 2569-2577.

Schwartz, M.D., and Hanes, J.M. 2010. Continental-scale phenology: warming and chill. Int. J. Climatol. 30, 1595-1598.

Wolfe, D.W., Schwartz, M.D., Lakso, A.N., Otsuki, Y., Pool, R.M., Shaukis, N.J. 2005. Climate change and shifts in spring phenology of three horticultural woody perennials in northeastern USA. Int. J. Biometeorol. 49, 303-309.

\section{$\underline{\text { Tables }}$}

Table 1. Description of the collected data.

Table 1 Summary of sites and flowering data used in this study

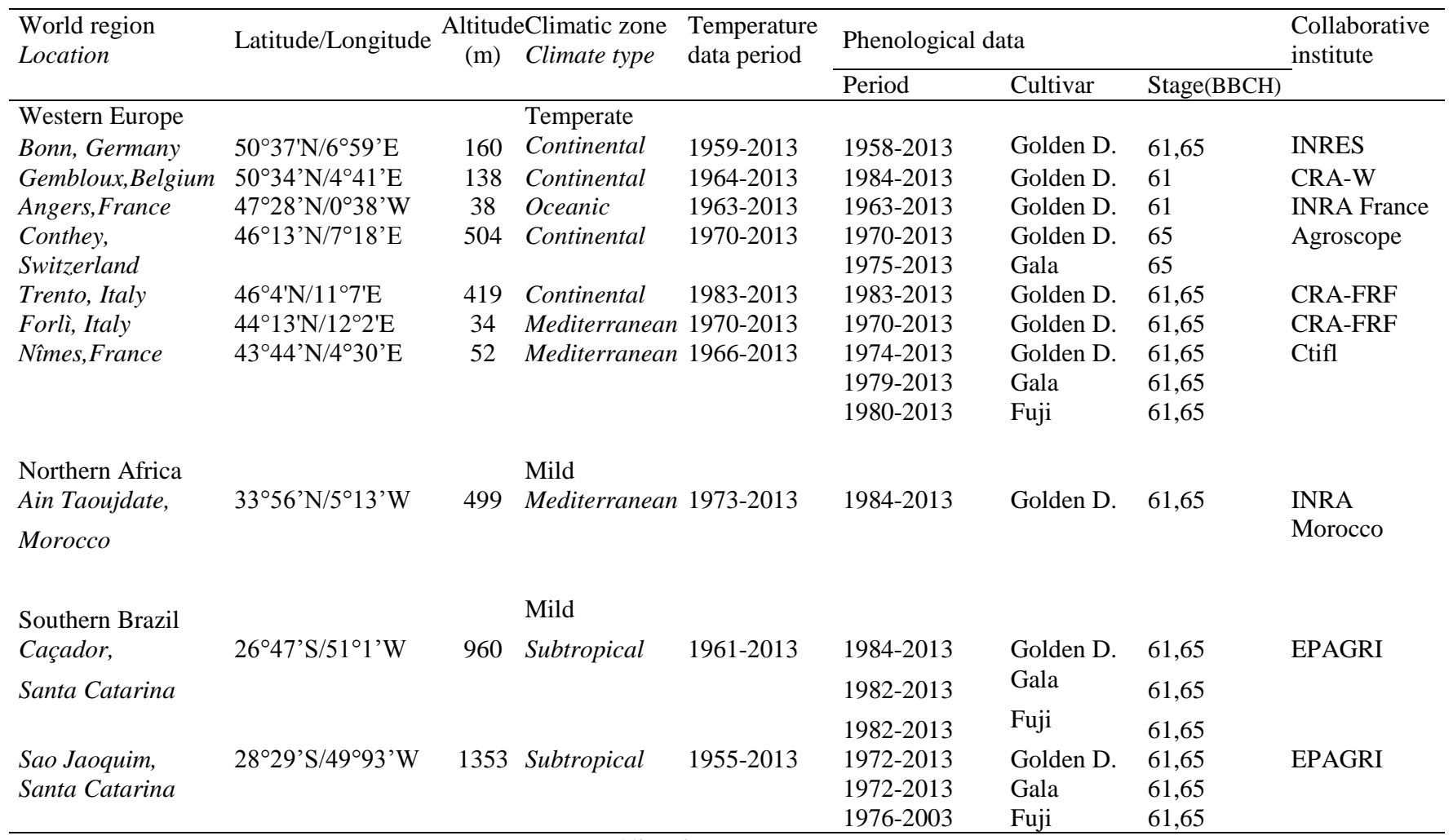


Pre-editorial text before Acta corrections

\section{Figures}

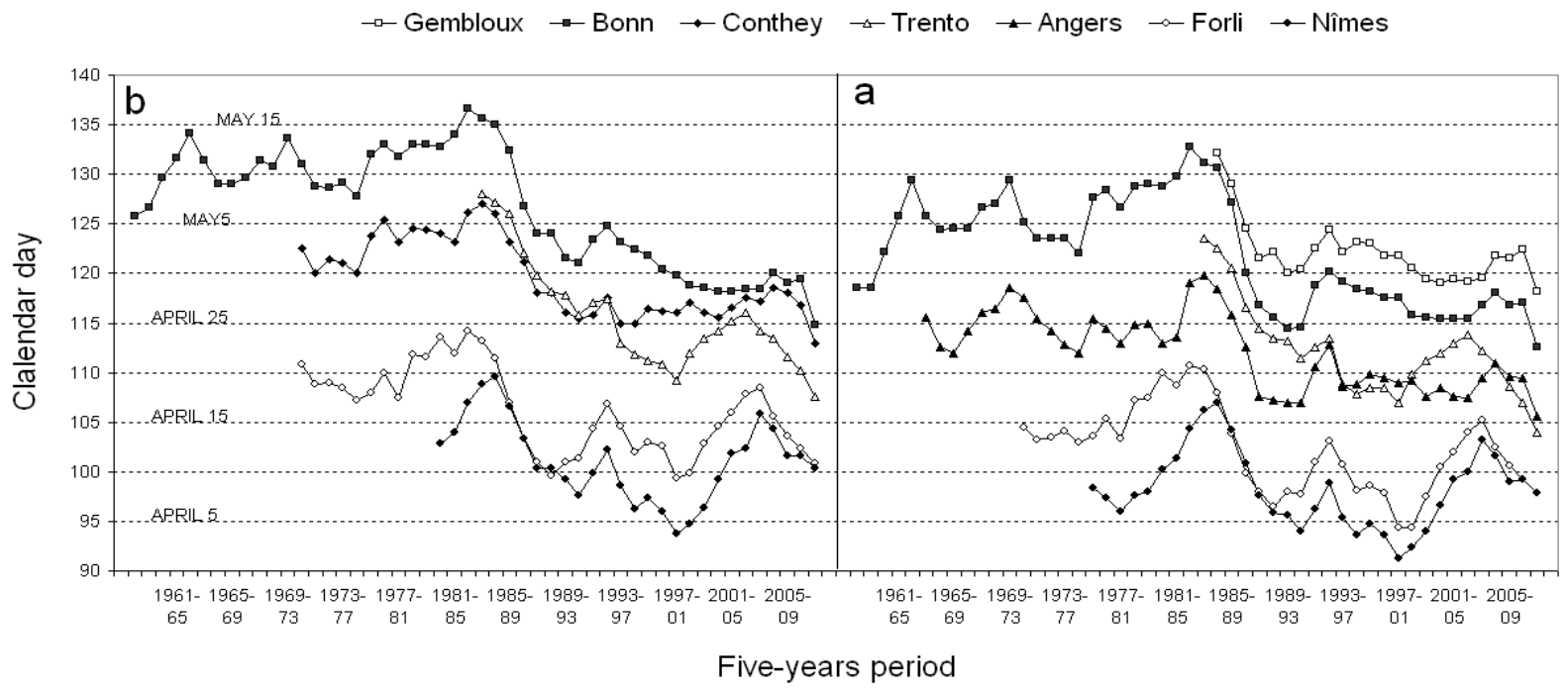

Fig. 1. Time-course changes (five-years moving averages) of observed annual dates of two flowering stages (a: BBCH 61; b: BBCH 65) recorded for G D at seven European locations.

$\square$ Duration of chilling period

Duration of forcing period

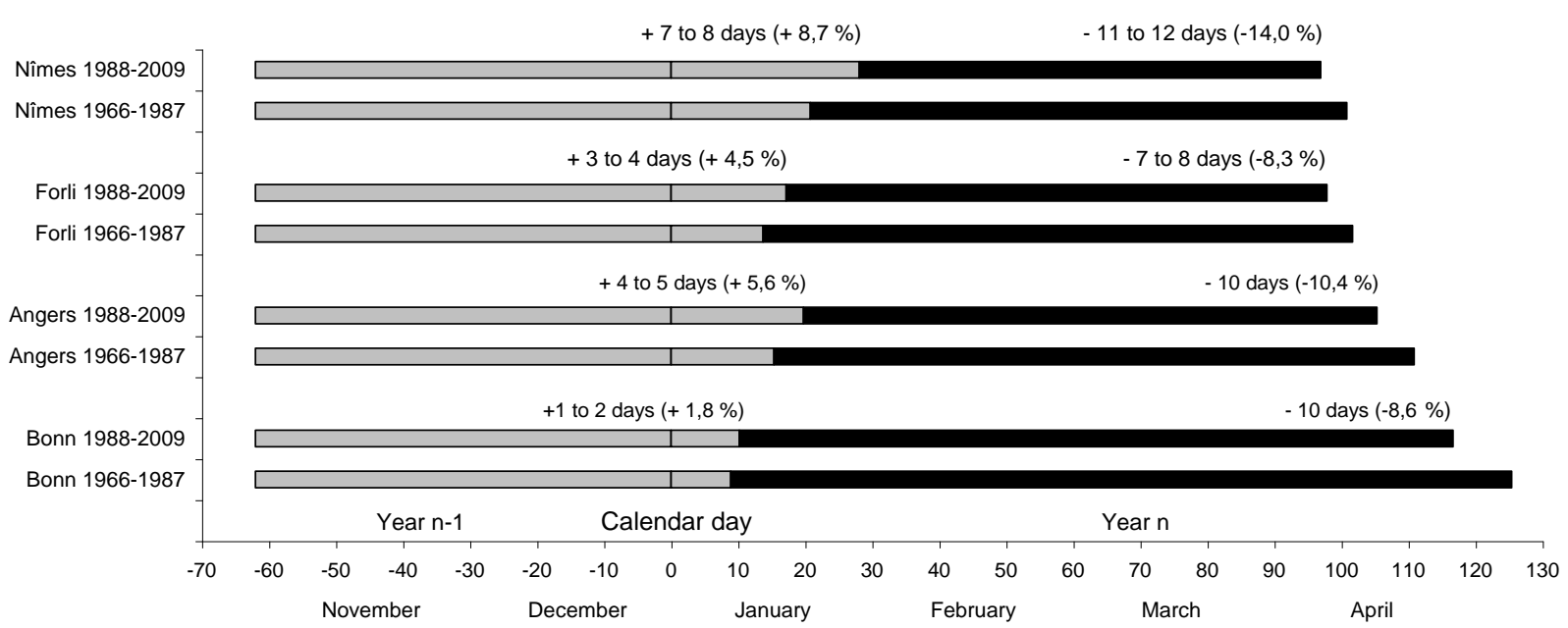

Fig. 2. Differences in the mean durations of chill and forcing periods between 1966-1987 and 1988-2009 for GD buds at four contrasting sites, as simulated by the F1Gold1 model. 
Pre-editorial text before Acta corrections
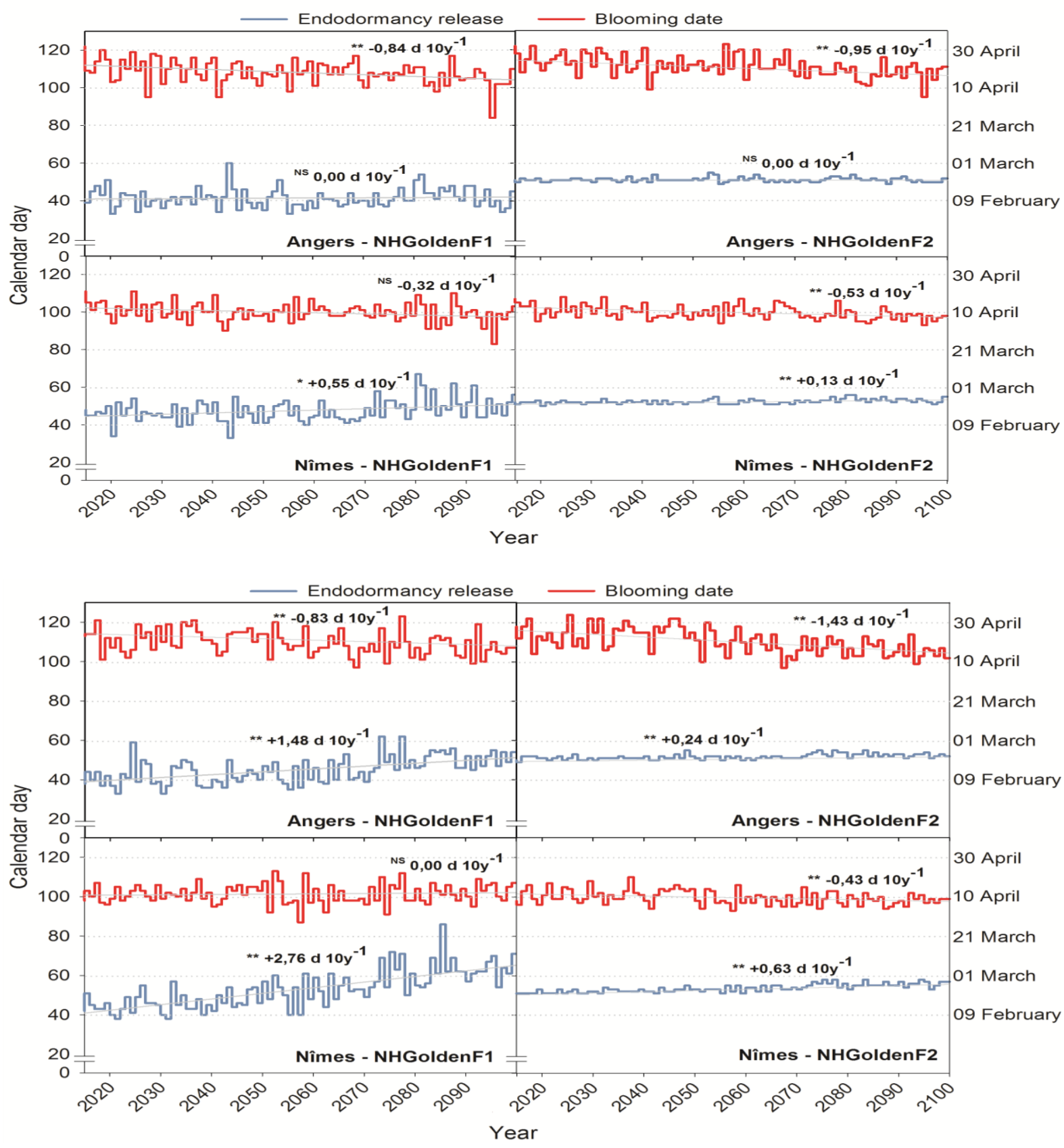

Fig. 3. Predicted dates of dormancy release and flowering time according to the $4.5 \mathrm{RCP}$ scenario (upper graph) and the 8.5 RCP scenario (lower graph) for GD in the oceanic French location (Angers) and Mediterranean French location (Nîmes). Different selected models were used: NHGoldenF1 for the prediction of the BBCH 61 date and NHGoldenF2 for the prediction of the $\mathrm{BBCH} 65$ date (In each graph: 61date on the left and 65 date on the right). 